\title{
Perceptions of Texas Public School Superintendents Regarding Online Teacher Education
}

Neil T. Faulk, Ed.D., McNeese State University, USA

\begin{abstract}
This study examined Texas public school administrator perceptions of online teacher education. Of primary concern were superintendent perceptions of online teacher education as it exists today. Data for the study were collected through the use of a survey questionnaire. The survey consisted of nine items where participants were asked to respond to a Likert scale format and one open-ended question in which respondents were asked to provide comments or suggestions regarding online teacher education. The researcher used regular and electronic mail to survey a random sample of one-hundred-fifty public school superintendents in the state of Texas. Seventytwo superintendents responded to the survey which represented a response rate of forty -seven percent. Based on the limitations of the study the following conclusions were made: Superintendents within the state of Texas apparently had negative opinions and perceptions regarding the use of online courses to train future teachers. A large majority of the superintendents did not fully agree that online courses or programs would fully prepare future teachers for conditions that would be faced within the public schools. Specific areas such as classroom management and the social aspects of teaching were not viewed as being positive in terms of online preparation. Other areas such as the theories and principles of teaching were viewed in a neutral light by the superintendents. Several of the administrators noted that online courses and programs would not be adequate without an abundance of field experiences and student teaching. Superintendents appeared to be very concerned that many of the teachers prepared online would possibly not endure the rigors of the classroom without having real classroom experience. Several administrators noted that future teachers needed to be taught by mentors in a real classroom setting in order to enhance modeling. Texas public school administrators appear to be open-minded to this new methodology but appear to be unconvinced that it will prepare teachers for the challenges that teachers face. Results agree with earlier results in two different regions of the country.
\end{abstract}

Keywords: teacher education, online teacher education, Texas public schools, public school superintendents

\section{INTRODUCTION}

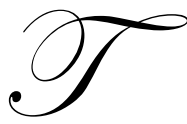

he use of the computer to educate has recently become very popular. Eastman and Swift (2001) noted that this rapid growth of computer online education had also spread into the field of teacher education with almost every college or university joining in with some type of online teacher education program or courses. This growth is parallel with the rapid growth throughout higher education in general. Santilli and Beck (2005) found that universities far and wide had jumped on the online bandwagon offering numerous courses and programs of a wide variety. At the present time one can easily observe that online education at the higher education level is growing in leaps and bounds.

Anyone associated with education at the college/university level can surely attest to the fact that online courses and programs are rapidly expanding. Much of this rapid change and expansion has been without objective research and definitely without honest intellectual discussion or empiricism. It appears as though higher education 
administrators have simply looked the other way in an attempt to perhaps make gains in student enrollment which would in turn create monetary benefits for their respective institutions. As of the year 2011 there were only two empirical studies attempting to ascertain the perceptions of consumers who were to eventually hire the graduates of these online programs. Huss (2007) stated that empirical research concerning online teacher education programs did not exist. It appears that the higher education administrators have implemented these programs without any empirical facts regarding the results of the online programs. It is rather apparent that this new methodology needs further investigation coupled with an honest intellectual discussion. When one sells a product it behooves the seller to ask the buyer his opinion concerning the product. Without input and advice from the buyer it is impossible to improve the product or simply to determine the worth and merit of the product. For these reasons it is imperative that public school officials be consulted regarding the preparation and education of future teacher candidates that are to be employed within these same schools.

\section{LITERATURE REVIEW}

The use of the computer and the electronic technology that complements the computer has rapidly grown at all levels of higher education. Almost every university now offers some type of computer online courses and most offer online programs in which all or most of the courses are taken via electronic means with a minimum of face to face real personal contact between instructor and student. There are many instructors and professors who claim that this electronic instruction is the future of teaching and the future of learning. Higher education administrators have jumped on the electronic bandwagon and have demanded that most programs of study have many online course offerings. Some universities have even refused to offer the traditional face to face instruction and have transitioned some programs totally to an electronic online format. It is interesting to note that this sudden transition to the electronic means has been done without the benefit of empirical research and an honest intellectual discussion. Gayton (2009) concluded that deans and vice-presidents unanimously agreed that face to face instruction was superior to the online electronic instruction. The same study revealed that deans and vice-presidents were extremely adamant about the immediate implementation of online courses and programs at their respective institutions. It is easy to determine or ascertain that perhaps the deans and vice-presidents have some alternative motive for their actions since it was unanimous that the electronic online instruction was inferior when compared to the traditional face to face instruction.

The area or field of teacher preparation and teacher education has also witnessed this rapid transition to the electronic online courses and programs. Eastman and Swift as early as 2001 noted that many universities were rapidly attempting to establish and maintain online courses and programs. Anyone who browses or sifts through any university course schedule or catalogue will no doubt notice many online courses being offered and some teacher education/preparation programs that are totally online. A recent trend reveals the blended curriculum becoming very popular. The blended curriculum consists of programs being partially online and partially face to face in the traditional mode.

It is both shocking and rather amusing that higher education administrators have not sought input or feedback regarding this transition to the new methodology. There has been little if any research or empiricism proving that online teacher education courses and programs are superior to the traditional format of preparing and educating teachers. One must remember that Gayton (2009) concluded that higher education academic administrators were unanimous in their belief that the traditional face to face format was superior to the online format. Still the higher education administrators have demanded that online courses and programs be expanded as quickly as possible. There have been only two studies attempting to ascertain the merits of online teacher education programs. The first study was conducted by Huss in 2007 within three states. Huss noted that most of the research prior to his study was conducted in order to ascertain how comfortable the faculty instructor was with the online format rather than on how effective the online prepared teachers were at actually teaching public school students. Huss also concluded in his initial study that public school superintendents and principals in the states of Kentucky, Ohio, and Indiana did not view online teacher education as being positive. The most interesting statistics to note from this study were that one-hundred percent of the public school administrators had concerns about online degrees and ninety-nine percent of the same group would definitely prefer to hire the teacher that had been trained and educated in the traditional format rather than in the online electronic format. Huss concluded from his research that public school administrators did not perceive that being trained via computer would prepare the future teachers in 
the areas of people skills, human interaction skills and social skills so desperately needed by the teachers within the public schools.

The second and final research study attempting to ascertain the possible effects of online educated teachers was done by Faulk (2010) within the state of Louisiana. Faulk surveyed all sixty-nine superintendents of public school districts and a random sample of one hundred-fifty principals in the bayou state. Faulk concluded that Louisiana administrators were open-minded regarding online teacher education since a slight majority perceived that it was desirable to prepare teachers in the areas of learning theory and in the areas of methodology/pedagogy. The overall conclusion reached by Faulk however was that public school administrators in the state were unconvinced that online courses or programs would prepare future teachers adequately. This conclusion was reached due to the fact that superintendents by a large majority did not think that areas of classroom management, social skills, and special needs and diversity would be adequately addressed within the online format. The most interesting statistic was that nearly ninety-percent of both superintendents and principals surveyed had moderate to strong reservations in hiring those teachers who had been prepared in the electronic online format. This conclusion agreed with earlier research by Huss within the states of Kentucky, Ohio and Indiana. Once again as in the earlier study by Huss many public school administrators did not believe that online courses or programs would come anywhere near preparing future teachers for the people skills, human interaction demands, and management skills that are expected when one must manage twenty-five to thirty human beings within a real classroom setting. Several administrators made comments and suggestions that the online courses were not a true picture of reality and that text in a computer or text in a book were no different and would not prepare teachers for the demands of the real job of teaching the youth of today. Other administrators strongly suggested that more field experiences, more practice teaching and more student teaching be implemented in order to take the future teacher out of the comfort zone of his home behind the computer and in the real public school classrooms of today.

\section{METHODS}

\section{Selection of a Population}

The researcher used a computer generated random table of numbers to select one-hundred fifty superintendents from a Master list of school districts and superintendents on the Texas Educational Agency website. This random sample of one-hundred fifty superintendents represented approximately eleven percent of all superintendents within the state of Texas. The researcher mailed the survey by regular mail and included a self addressed stamped envelope in order for the subjects to return the survey. Subjects were also contacted via email in order to request cooperation with the study. Seventy-two superintendents returned the survey via regular mail which represented a response rate of forty-seven percent.

\section{The Data Gathering Instrument}

Validity was established by a panel of experts. The panel included five professors of teacher education, three professors of online teacher education, two English professors and one psychology professor. The panel eventually agreed that the survey would indeed ask pertinent questions in an unbiased manner relating and regarding the use of online teacher education to prepare future teachers. Reliability had been established by the test-retest method with .94 being the measure of temporal stability. It might also be worthy to mention that the questions were originally derived through a close observation of education courses offered by twenty universities within bachelor of education programs. The survey had nine questions that were in the Likert scale format and one open ended question asking the respondents suggestions or comments regarding online teacher education. Online teacher education was defined within the survey as a teacher education program with a large majority of the coursework being done by electronic means via computer technology thus greatly minimizing the face to face real personal contact between instructor and student.

\section{RESULTS}

The major purpose of this study was to determine perceptions of Texas public school superintendents regarding online teacher education. Seventy-two of the one-hundred fifty superintendents surveyed responded by returning the survey. This represented a response rate of forty-seven percent. 


\section{Question 1}

What is your opinion of online teacher education(OTE) ? Sixty five percent of the superintendents responded either Very Unacceptable or Slightly Unacceptable which indicated a negative perception of OTE. Thirty five percent of the superintendents responded either Highly Desirable or Slightly Desirable which indicated a positive perception of OTE. It is obvious that superintendents have a more negative perception of OTE.

\section{Question 2}

What is your opinion of OTE in terms of preparing future teachers for classroom management? Seventy-two percent of the teachers responded either Very Unacceptable or Slightly Unacceptable which indicated a highly negative perception of OTE and classroom management preparation. Only eighteen percent of the superintendents responded Highly Desirable or Slightly Desirable which indicated a weak positive perception of OTE and classroom management preparation. It is rather obvious that superintendents have a strong negative perception of OTE and classroom management preparation.

\section{Question 3}

What is your opinion of OTE in terms of preparing future teachers in the methodology of teaching?

Fifty percent of the superintendents responded either Very Unacceptable or Slightly Unacceptable while fiftypercent responded Highly Desirable or Slightly Desirable. Principals appear to have mixed views on this topic or appear to be neutral regarding OTE and methodology of teaching.

\section{Question 4}

What is your opinion of OTE in terms of preparing teachers for student diversity and special needs?

Sixty-eight percent of the superintendents responded either Very Unacceptable or Slightly Unacceptable. Thirty four percent of the superintendents responded either Highly Desirable or Slightly Desirable. Principals appear to not have confidence that OTE will prepare teachers for diversity and special needs.

\section{Question 5}

What is your opinion of OTE in terms of preparing future teachers in learning theories and principles?

Sixty-four percent of superintendents responded Highly Desirable or Slightly Desirable. Thirty eight percent of superintendents responded Very Unacceptable or Slightly Unacceptable. Principals appear to believe that OTE is sufficient to prepare teachers for theories and principles of learning.

\section{Question 6}

What is your opinion of OTE in terms of preparing future teachers for the social aspects of teaching?

Seventy-nine percent of the superintendents responded Very Unacceptable or Slightly Unacceptable. Only twentyone percent of the superintendents responded Highly Desirable or Slightly Desirable. It is apparent that superintendents do not perceive OTE as preparing future teachers for social demands and social skills needed by teachers.

\section{Question 7}

Would you have any reservations in hiring future teachers in your district that have been trained primarily using OTE?

Seventy-nine percent of the superintendents responded that they had moderate to strong reservations in hiring teachers trained primarily with OTE. Only twenty-one percent of the superintendents responded that they had little or no reservations in hiring OTE trained teachers. Apparently superintendents do not care to hire the OTE trained teachers. 


\section{Question 8}

What is your perception of the academic security and academic integrity of OTE courses currently being offered? Fifteen percent of the superintendents responded that OTE courses had High levels of Security while fifty-seven percent responded that Slight to Moderate levels of security and integrity existed. Twenty-eight percent responded that Little or No security and integrity were present. It is apparent that there are mixed perceptions regarding this question with a slight lean toward the positive in terms of security and integrity of OTE courses.

\section{Question 9}

What is your present level of knowledge concerning the use of OTE? Thirty-two percent of the superintendents responded that they had High levels of knowledge concerning OTE while fifty-seven percent responded that they had Slight to Moderate levels of knowledge. Only nine percent of the superintendents responded that they had Little to No Knowledge concerning the use of OTE. Overall the results show that the majority of superintendents do have knowledge about the use of OTE.

\section{Question 10}

The final question of the survey was an open-ended question asking superintendents for suggestions or comments regarding the use of OTE. Twelve percent of the superintendents gave comments or suggestions.

Most of the comments were negative regarding OTE . The main criticism was that the OTE preparation would not prepare teachers for the reality of managing human behavior in a real world setting. OTE was looked upon as being artificial and not preparing teachers for what teaching is really all about in terms of dealing with different children and different personalities. There was one positive comment that OTE had helped fill shortage area positions within a school district. Another positive comment was that it helped rural districts located far distances from the university setting. Overall comments were negative.

A summary of the questions and responses is as follows:

Question 1---Overall perception of OTE

Question 2---Classroom Management Preparation

Question 3---Methodology Preparation

Question 4---Diversity, Special Needs Preparation

Question 5---Theories of Learning Preparation

Question 6---Social Aspects Preparation

Question 7---Reservations in Hiring OTE teachers

Question 8---Security and Integrity of OTE

Question 9---Superintendent Knowledge of OTE

\author{
Negative $65 \%$ \\ Negative $72 \%$ \\ Mixed or Neutral $50-50 \%$ \\ Negative $68 \%$ \\ Positive- 64\% \\ Negative $79 \%$ \\ Negative $79 \%$ \\ Neutral or Mixed \\ Adequate level of Knowledge
}

\section{CONCLUSIONS}

The results of this study tend to strongly agree with the two other studies done in different states. There appears to be a definite negative opinion toward online teacher education by a large majority of superintendents within the state of Texas. This conclusion can easily be reached and defended in observation of the critical questions and responses on the survey. Anyone who has any background in public school teaching knows that without the critical human social skills of classroom management the teacher will not stand a chance of educating the children in any subject matter or content area. Many an educator wishes that this were not true, but once within the public school and once within actual classrooms it is rather apparent that the teacher who cannot control, manage, and motivate the children has little if any chance of success. The classroom teacher of today even more than the classroom teacher of twenty years ago must be able to get students not only to cooperate but also must motivate the students to participate in intellectual activities and discussions. The superintendents of Texas apparently are very aware of these facts and do not believe that online prepared teachers will be able to handle and adjust to the social and human interaction demands necessary to succeed as a classroom teacher in our schools of today. There was an 
old saying that veteran educators stated for many years. The saying was "if you can't control them--you sure as heck can't teach them". Apparently superintendents still feel strongly about this and do not think that social skills and human interaction skills can be learned by sitting and working on a computer within the comfort zone of one's home. The response to the classroom management question may be the most important response since successful teaching cannot occur without successful classroom management.

The majority of the other questions were responded to in a negative manner by the superintendents so it should be easy to ascertain that superintendents have negative perceptions regarding online teacher education and preparation. Another critical question that evoked critical responses was the question regarding whether or not the superintendents had reservations in hiring online prepared teachers. Once again a large majority of the superintendents do not want to hire online prepared teachers so it should be easily apparent that superintendent perceptions are indeed quite negative to the online format of educating future teachers. Superintendents do appear to be open-minded to the online format since a majority responded positively to learning theories preparation and a near majority responded positively to methods and pedagogy preparation.

The lack of confidence that superintendents have towards online prepared teachers definitely needs to be addressed by university administrators who are blindly attempting to transition some entire degree plans and programs to the online electronic format. These same university administrators have been surveyed and results show that perceptions are not in favor of online courses being superior to the traditional format. Perhaps the university administrators should look beyond the monetary short term benefits of today and think about the long term consequences of not adequately preparing a generation of teachers for the critical aspects of the teaching profession. One may argue this point but in three separate studies in five different states the public school superintendents and principals had little faith and confidence in the merits of online teacher education programs. Many believe that our most professional and conscientious educators are our public school personnel who perform admirably and do great deeds in the face of insurmountable odds. If we do respect and admire the professionalism of our superintendents and principals who originated from the teaching profession then perhaps university administrators should take heed and listen to the consumers of their products.

It is recommended that further research be done within more states and within different regions of the country on this topic. It is also recommended that veteran teachers who have been deemed successful be surveyed regarding the merits of different types of instructional formats. A large majority of educators at all levels do indeed strive to have excellent public school teachers but apparently a large majority of educators at all levels do not agree on what is the optimal route to arrive at that destination.

\section{AUTHOR INFORMATION}

Dr. Faulk began his career as a teacher in the public schools of Louisiana. His experience includes seventeen years at the public school level and twelve years at the university level. Dr Faulk earned his Doctorate of Education at Texas A\&M University at College Station, Texas in 1993.

\section{REFERENCES}

1. Eastman, J. \& Swift, C. (2001). New horizons in distance education: The online learner-centered marketing. Journal of Marketing Education, 23(1), 25-34.

2. Faulk, N. (2010). Online Teacher Education--What Are the Results. Contemporary Issues in Education Research, 3 (11), 21-28.

3. Gayton, J. (2009). Analyzing online education through the lens of institutional theory and practice: The need for research based and validated framework for planning, designing, delivering, and assessing online instruction. Delta Pi Epilson Journal, 51 (2), 62-75.

4. Huss, J. (2007) Attitudes of middle grade principals toward online teacher preparation programs in middle grades education: Are administrators pushing "delete"? Research in Middle Level Education, 30 (7) 1-12.

5. Santilli, S., \& Beck, V. (2005). Graduate faculty perceptions of online teaching. Quarterly Review of Distance Education, 6(2), 155-160. 